\title{
Cine, poder e historia: la representación y construcción social del indígena en el cine ficción venezolano durante la década de los años 80
}

Cinema, power and history: the representation and social construction of the aborigen in the venezuelan fiction cinema during the decade of the 80 s

Fidel Rodríguez Velásquez

Antropólogo, Universidad Central de Venezuela (UCV) Maestría en Historia de las Américas, Universidad Católica Andrés Bello (UCAB) fidelrodv@gmail.com

Artículo de investigación DOI: http://dx.doi.org/10.15332/s2339-3688.2016.0001.01 Fecha de recepción: Noviembre 19 de 2015 • Fecha de aprobación: Marzo 28 de 2016

\section{RESUMEN}

El presente artículo analiza desde una perspectiva histórico-antropológica al cine como vehículo en el que se relacionan de forma directa o indirecta el poder (estatal) y la historia (historia oficial) en la representación del indígena venezolano durante la década de los años 80 , utilizando la noción de historia de Gaskell (1996) quien la entiende como "el discurso elaborado por los historiadores y no el pasado", y lo señalado por Iglesias (2013) cuando esboza que "el cine tiene un papel político crucial como mediador del imaginario colectivo a la hora de construir identidades", para ello se realizó un análisis crítico del discurso que sobre los pueblos indígenas venezolanos están contenidos en las películas: Caballo salvage (1981), Orinoko, nuevo mundo (1984) Ya-koo (1985), Cubagua (1987) y Amérika, terra incógnita (1988) a la luz de las ideas que de estos se impulsaron desde el Estado Venezolano.

Palabras clave: cine, pueblos indígenas, otredad, ideología, construcción del pasado. 


\begin{abstract}
The present article analyzes from a historical-anthropologic perspective cinema as vehicle in which there are related of direct or indirect form the (state) power and the history (official history) in the representation of the Venezuelan aborigen during the decade of the 80 s, using the notion of history of Gaskell (1996) who understands it as "the speech elaborated by the historians and not the past", and indicated by Pablo Iglesias (2013) when it outlines that "the cinema has a political crucial role as mediating of the imaginary group at the moment of constructing identities". For this a critical analysis of the speech was done on the indigenous Venezuelan people contained in the movies: Caballo salvage (1981), Orinoko, nuevo mundo (1984) Ya-koo (1985), Cubagua (1987) and Amérika, terra incognita (1988) in the light of the ideas that were stimulated about these indigenous people since the Venezuelan State.
\end{abstract}

Keywords: Cinema, indigenous peoples, otherness, ideology, construction of the past. 


\section{Preliminares}

Se empezará por rechazar cualquier noción de neutralidad y falta de intención en las producciones cinematográficas, puesto que se considera que las mismas buscan de manera consciente o inconsciente, desde una posición de poder, imponer sobre la sociedad ideas, valores, costumbres y formas de entender el mundo en su presente y su pasado. Esta postura permitirá analizar el cine en un marco más amplio, es decir, como un producto cultural de su tiempo influenciado por la mirada de quienes están en la capacidad tecnológica de construir productos audiovisuales. Estas miradas se encuentran fuertemente cargadas de ideología y toman forma de ideas cuando son transmitidas a lo interno de las clases que la producen, y de falsa conciencia cuando se imponen a grupos subalternos.

En el presente trabajo se utilizará la noción de historia de Gaskell (1996), quien la entiende como "el discurso elaborado por los historiadores y no el pasado" (p. 209), es decir, se analizará la historia, formas de hacer historia y formas de difundir la historia como productos de tipo cultural. Así mismo, se considerará central lo señalado por Pablo Iglesias (2013) cuando argumenta que "el cine tiene un papel político crucial como mediador del imaginario colectivo a la hora de construir identidades" (p. 17). Ambas cuestiones colocan sobre el tapete aquello que puede denominarse los usos políticos del pasado, es decir, las formas como los diversos discursos históricos cumplen una función en la sociedad, cómo cada grupo de poder construye un discurso histórico con base en su proyecto político propio y cómo dependiendo de quién detente el poder, estos discursos toman cuerpo en una historia oficial difundiéndose en la población a través de los aparatos ideológicos del Estado.

La presente investigación centró su fuerza en el análisis del cine como una de las formas audiovisuales con más influencia a la hora de generar representaciones colectivas y de construir visiones sobre el pasado, a partir del estudio de la representación y construcción social del indígena venezolano en el cine ficción de la década de los años 80, sopesando la influencia que en esta representación tuvo la historia oficial y sus usos políticos. Para ello, se analizaron los discursos sobre los pueblos indígenas venezolanos contenidos en las películas: Caballo salvage (1981), Orinoko, nuevo mundo (1984), Ya-koo (1985), Cubagua (1987) у Amérika, terra 
incógnita (1988) y las posturas que sobre el pasado indígena tuvieron tres de los intelectuales venezolanos con mayor influencia en la construcción de la historia oficial imperante en la década de los años 80, estos fueron Laureano Vallenilla Lanz, Arturo Uslar Pietri y Guillermo Morón. Con ello se buscó establecer las relaciones de tipo ideológica entre los mismos y sopesar la influencia de la historia oficial en las producciones cinematográficas.

\title{
EL CINE Y LA HISTORIA, CONSIDERACIONES PARA SU ESTUDIO
}

\author{
El cine tiene un papel politico crucial como mediador \\ del imaginario colectivo a la hora de construir identidades
}

(Iglesias, 2013, p. 17).

Como hemos mencionado, uno de los medios audiovisuales más importantes, sin duda, lo constituye el cine, puesto que como institución social puede entenderse en términos de Mauss (1979) como un "fenómeno social total" debido a que en el cine "se expresan a la vez y de golpe todo tipo de instituciones: las religiosas, jurídicas, morales (tanto políticas como familiares) y económicas" (p. 157), es decir, se expresan las formas de entender y comprender el mundo de los sectores sociales que lo producen, por ello, si se pretende historiar el cine y en particular el cine venezolano, es requisito ineludible relacionar su producción con el momento político, económico y social que vivió el país en su contexto.

En relación al cine y su papel en la construcción histórica pueden observarse dos posibles rutas de análisis, el mismo se entiende en términos de un discurso histórico que pretende ser transmitido y como un producto cultural de su tiempo (Acosta, 2003), este último teniendo presente que estará siempre social e históricamente determinado. Estas consideraciones muestran la relevancia del cine como objeto de estudio, puesto que nos encontramos ante un medio audiovisual que construye historia a la vez que es construido por la historia, ambos procesos indiscutiblemente mediados por el poder y sus intereses. No en vano Nietzsche (2008) definió a la historia como la lucha por imponer mi poder al poder del otro, cuestión central para analizar al cine como un espacio de disputas en la construcción de historias, puesto 
que, si entendemos la historia como un campo de batalla, el cine entonces podría catalogarse como un escenario relevante a la hora de resolver esta batalla en favor de uno u otro grupo, debido al poder de los discursos visuales en la construcción de miradas hegemónicas sobre los sujetos representados.

En esta línea de ideas es necesario destacar algunas limitaciones a las que se enfrenta el investigador en su tarea de construir y reconstruir el pasado, limitaciones que, sin duda, son trasladadas al cine cuando lo estudiamos como un documento histórico y un producto cultural. La primera de ellas tiene que ver con quienes son los sujetos que se encuentran en la capacidad tecnológica de producir fuentes, en este caso películas de cine. Al respecto Ginzburg (2004) señala que "la producción de fuentes de una determinada sociedad, está ligada de manera directa a las relaciones de fuerza que existen al interior de esa misma sociedad determinada” (p. 122), señalamiento que se desprende cuando utilizamos las fuentes audiovisuales como una versión de la historia, construida por un sector específico de la sociedad con intereses políticos, económicos y sociales (Navarrete, 2006). Por tanto, esta versión de la historia será siempre parcial e interesada en mostrar y realzar las visiones del sector de la sociedad al que pertenecen y opacar o representar de forma despectiva al resto de los sectores de la sociedad.

Otro elemento a señalar es el referido a la creación y constitución de los archivos fílmicos, así como a los mecanismos de distribución y exhibición de los productos cinematográficos, puesto que de ello dependerá la duración del producto fílmico en el tiempo y su influencia en la memoria de la nación, situación que, sin duda, dependerá de la efectividad de su exhibición en las salas de cine, así como de su distribución por otras vías como los cineclub o cines comunitarios. Estos aspectos están condicionados a la relación del cine con el poder, la cual determina la posibilidad de construcción y visibilización de miradas alternativas del pasado, puesto que aquel film que no esté alineado ideológicamente con los grupos hegemónicos de la sociedad, podrá terminar, en el peor de los casos, censurado y su exhibición prohibida o simplemente no ser exhibida en las principales salas de cine, limitando significativamente la influencia de sus ideas sobre la sociedad. 
Las consideraciones anteriores muestran la complejidad que envuelve el estudio del cine si se entiende este como un producto cultural, lo cual obliga al investigador a un análisis minucioso de múltiples factores, por ello, se utilizó como enfoque metodológico el paradigma indiciario propuesto por Carlo Ginzburg (2004) quien lo define como "un método interpretativo apoyado sobre los descartes, sobre los datos marginales, considerándolos como reveladores. De este modo, detalles estimados habitualmente sin importancia, o directamente triviales, 'vulgares' suministran la clave para acceder a los productos más elevados del espíritu humano” (p. 105). Cabe destacar que este método tiene sus orígenes en el estudio de las pinturas, por lo que su uso en el análisis del cine sería como una vuelta a sus orígenes en el mundo de las artes.

También es importante señalar que este paradigma metodológico lleva consigo varias consecuencias de orden epistemológico, la primera de ellas es que la posibilidad de reconstruir el pasado y las visiones que de él tenían quienes produjeron cine, pasa por un complejo proceso que va de la observación al análisis y de este a la interpretación. Dicho proceso obliga al investigador a considerar darle a las fuentes fílmicas que son objeto de estudio una mirada más profunda, de la que no solo se puede obtener lo explícitamente dicho en ellas, sino también una mirada en la cual puedan interpretarse hasta los silencios y lo no dicho. Asimismo, asume como un recurso interpretativo válido las analogías puesto que las mismas expresan, "la semejanza de una cosa con otra, la similitud de unos caracteres o funciones con otros mediante la atribución de los mismos predicados a diversos objetos" (Navarrete, 2006, p. 224).

\section{Cine, PODER E IDEOLOGÍA}

\section{La ideología no debe ser entendida como la entienden los ideólogos, la ideología debe ser descrita y explicada cientificamente, como se explica cualquier otro fenómeno caracteristico de la historia humana}

(Silva, 2011, p. 60).

La cultura entendida en el sentido otorgado por Claude Levi-Strauss (1995), cumple un papel central en la sociedad, puesto que la misma homogeniza a los grupos 
humanos según unos códigos, signos y símbolos específicos. Sin embargo, esta homogenización no ocurre de forma aleatoria, puesto que será el resultado de la contraposición en el seno de la sociedad de las relaciones de poder entre grupos hegemónicos, esta lucha tiene como objetivo final imponer al resto de la sociedad los intereses de los grupos que detentan el poder, es por ello que Marx y Engels (2013) en su libro Crítica a la ideología alemana, afirman que "las ideas de la clase dominante son las ideas dominantes en cada época” (p. 30).

Pero la pregunta en este proceso sería, ¿cómo ocurre tal dominación? Desde nuestra perspectiva el concepto clave para entender la dominación en este proceso es el de Industria cultural, desarrollado por Horkheimer y Adorno (1988) debido a que en él se revela la dimensión ideológica de aquello que era considerado simple entretenimiento neutral. A partir de este momento cine, televisión, radio y cómics pasan a ser el centro de una importante industria que, a través de su construcción ideológica del mundo, tendría como fin último el de universalizar los significados, es por ello que Silva (2011) plantea que "la industria cultural se revela como el típico lugar de la ideología” (p. 211).

Esta lucha por los significados tiene en el seno de la sociedad dos campos de realización: el campo ideológico y el campo cultural. La diferencia entre uno y otro radica en el grupo social que se tenga por objeto de estudio, es por ello que cuando nos referimos a la sociedad es necesario aclarar que cuando se habla de ideología se refiere a un proceso específico en el que las ideas de los grupos dominantes son apropiadas por los grupos subalternos, y por tanto sus prácticas son el resultado de la defensa de los intereses de los grupos hegemónicos. Como señala Guzmán (2009), “el saber ideológico se sostiene desde una estructura lingüística que reside en el inconsciente, en el preconsciente y en la conciencia, para dictarnos el camino de lo que debemos defender" (p. 12). La práctica diaria de forma inconsciente hace de la ideología una práctica cultural, esto revela que la universalización de significados que tiene como meta la industria cultural, solo es posible en la medida en que los contenidos ideológicos se hagan práctica diaria inconsciente como contenidos culturales.

En el marco de esta industria cultural, destacamos el papel del cine, por su amplia capacidad de influir en las personas (Mora, 2017), pero sobre todo a la hora de 
construir representaciones ideológicas tanto del otro como de sí mismos, y transmitirlas a la sociedad como ciertas. Es por ello que su vinculación con el poder no es nada nuevo, se podría decir que data desde su génesis misma, un ejemplo de ello se observa en la utilización que han hecho del cine los clásicamente denominados “regímenes totalitarios” del siglo XX. Para los soviéticos el cine era la más importante de todas las artes, y bajo el lema "un cine revolucionario para la revolución", se desarrollaron películas como El acorazado Potemkin (1925) de Serguéi Eisenstein y Octubre (1928) de Grigori Aleksándrov. Por su parte, los nazis hicieron lo propio y convirtieron al cine en su gran aparato ideológico, llevando adelante películas como Juventud de Hitler (1933) y Colgados, mujeres y soldados (1935). Pero, los usos políticos del cine no se limitaron a estos regímenes, en "grandes democracias" como la estadounidense el cine también jugó un papel central. En medio de la Guerra Fría, en 1947 la Comisión de Actividades Antiestadounidenses inició un proceso legal contra 79 importantes figuras del cine norteamericano bajo la acusación de promover el comunismo en sus películas, muchas de estas figuras tuvieron que huir del país y otras fueron sentenciadas a varios años de prisión e incluidos en listas que prohibían su participación en proyectos cinematográficos (Crespo, 2009). Como se observa en el siglo XX, el cine en distintos lugares del mundo y en distintas formas de gobierno ha jugado un papel importante, puesto que se ha utilizado para construir socialmente según sus intereses tanto al otro, como a sí mismos. Es decir, ha sido utilizado para imponerle a la sociedad quiénes son los "buenos" y quiénes son los “malos”, en definitiva, qué es lo "bueno" y qué es lo "malo".

Este pequeño recorrido seguramente despertará otros interrogantes en quienes leen este texto, sobre todo en el marco del mundo occidental del siglo XXI, donde han sido tan divulgados los planteamientos de Fukuyama (1992) sobre que la caída del muro de Berlín significó el fin de las ideologías y el inicio de un mundo marcado por la libertad y el libre mercado, estos interrogantes seguramente apuntarán sobre el concepto mismo de ideología y sobre su vigencia en la actualidad, ante estos cuestionamientos afirmamos que Fukuyama se equivoca y que paradójicamente su planteamiento del fin de las ideologías es también un planteamiento ideológico. 


\title{
LOS SENTIDOS POLÍTICOS DEL PASADO Y LOS PUEBLOS INDÍGENAS DE VENEZUELA
}

\begin{abstract}
Invisibles para la cultura dominante que motejó y aún tiene por dialectos sus lenguas, por supersticiones sus creencias, por bagatela sus artes, por salvajismo sus saberes, por indolencia su comeditamiento, por desidia su prudencia, por idiotez su paciencia,por turbas sus manifestaciones, por hordas sus manifestaciones, por menesteroso o despreciable su pan
\end{abstract}

(Pereira, 2010, p. 10).

Los proyectos políticos impulsados por los gobiernos venezolanos a partir de la toma del poder de Antonio Guzmán Blanco (1870) tuvieron como idea central el llamado "progreso de la nación” y la consecuente producción de una historia nacional, donde las elites ocupaban un sitial de honor y donde no había espacio para la historia de otros grupos sociales como los pueblos indígenas, y cuando lo había era para señalar un pasado remoto, su "desaparición" o su nulo aporte al desarrollo nacional.

Esta "historia nacional" tomó fuerza a partir de 1911 con la puesta en marcha de un nuevo currículo nacional bajo las ideas del positivismo venezolano (Mora-García, 2004), el cual se encargó de excluir sistemáticamente a los pueblos indígenas del proyecto nacional, inculcando en la población la idea de que los pueblos indígenas fueron cosas del pasado y que el "progreso de la nación” necesita de un país moderno donde los pueblos indígenas que aún existieran debían "civilizarse” e incorporarse a la vida nacional.

Es justamente en esta época cuando aparece en la escena política venezolana uno de los intelectuales que tenemos por objeto de estudio, nos referimos a Laureano Vallenilla Lanz, quien además de ser uno de los principales intelectuales defensores del gobierno de Juan Vicente Gómez, llegó a ocupar la presidencia del Senado en diversas ocasiones entre los años de 1920 y 1931, y la dirección de la Academia Nacional de la Historia entre 1924 y 1927 (Harwich, 1983). Su postura sobre los pueblos indígenas muchas veces defendida puede resumirse en uno de sus discursos donde señala: 


\begin{abstract}
"Tampoco existe un arte precolombino porque desde el punto de vista estético son insignificantes los cacharros de arcilla y los ídolos que improvisados etnólogos y arqueólogos vernáculos presentan como pruebas de la existencia de pretéritas civilizaciones. (...) Nosotros no somos anti-indigenistas, pero nos felicitamos que en Venezuela no hay indios y nos oponemos al mantenimiento de tradiciones que son fruto de la miseria, de la ignorancia y el atraso" (Vallenilla Lanz, citado en Castillo, 2003, pp. 110-111).
\end{abstract}

La negativa de Vallenilla a aceptar siquiera la existencia de los pueblos indígenas carecía de todo sustrato empírico, por ello no dudamos en catalogarlo de una postura ideológica y no científica como se intentó hacer parecer en su momento (Vargas, 2005). Esta postura anti-indígena tuvo continuidad, con sus matices, en el que es considerado por muchos el intelectual más importante del siglo XX venezolano (Arráiz, 2010), nos referimos a Arturo Uslar Pietri, de quien no desconocemos sus importantes aportes al momento de señalar los rumbos de la nación venezolana, pero que al referirse a los pueblos indígenas se apartó de su característico pensamiento científico y humanista para dar cabida a posturas ideológicas sobre el pasado y presente de los pueblos indígenas venezolanos. Su discurso central giró en torno al mestizaje y la idea de un hombre nuevo americano, su idea más difundida se expresa en la afirmación de que Venezuela es un crisol de razas donde:

"Lo que surgió no era, ni podía ser europeo, como tampoco pudo ser indígena o africano. Las tres culturas, en grado variable, se combinaron y mezclaron para crear un hecho diferente todavía no enteramente reconocido ni definido, que se reflejó en todas las formas de vida, de mentalidad y de la relación de las gentes" (Uslar, 1987, citado en Amodio, 1999).

Las ideas de Uslar Pietri fueron ampliamente difundidas por todos los medios escritos y audiovisuales de Venezuela (Barreto, 1995), cabe recordar que el mencionado autor se desempeñó como ministro de Educación durante el gobierno de Eleazar López Contreras y secretario de la Presidencia de la República, ministro de Hacienda y ministro de Relaciones Exteriores durante el gobierno de Isaías Medina Angarita, también se desempeñó como senador de la República, miembro de la Academia 
Nacional de la Historia y embajador permanente de Venezuela ante la Unesco, y por muchos ańos condujo el programa televisivo Valores humanos (Arráiz, 2010).

Si bien Uslar Pietri puede ubicarse como el gran masificador de estas ideas sobre el pasado y presente de los pueblos indígenas venezolanos, es necesario mencionar que en la producción de textos educativos, la más grande influencia la tuvo Guillermo Morón, a quien podríamos ubicar como una continuidad de los dos autores mencionados anteriormente y que en su obra más importante y difundida Historia de Venezuela (1971), solo dedica la primera página a los pueblos indígenas señalando lo siguiente:
"Desde el siglo XVI hasta el siglo XVIII, cuando existieron grandes masas indígenas, el hombre criollo se acercó de una u otra forma a los grupos de pobladores primitivos y se realizó un cruzamiento. Una insensible asimilación dio por resultado que el indio forme en la base social de nuestro pueblo un grueso sector, imposible de determinar. Ciertos rasgos de orden puramente cultural, sin que haya habido aportación en cuanto a la cultura intelectual. Ninguna idea general, ninguna manera de comportamiento -moral, derecho, religión, letras, lengua- proviene de los aborígenes" (Morón, 1971, p. 6).

Si bien estas posturas fueron fuertemente rebatidas por otros intelectuales de la época como Julio Cesar Salas (1908; 1977) y Miguel Acosta (1948; 1961), la historia oficial masificó la versión de los primeros, puesto que era esta historia la que tributaba a los intereses del proyecto de "modernización" impulsados por los diferentes gobiernos de Venezuela. Llama poderosamente la atención que la postura sobre el pasado y presente de los pueblos indígenas venezolanos, fuera casi exactamente la misma en tiempos de la dictadura Gomecista que en tiempos de la llamada democracia. $\mathrm{Al}$ respecto, Gramsci (1932) afirma que cada grupo social produce sus propios intelectuales en el marco de una estructura económica y social concreta, y dentro del grupo de los intelectuales, surgen un grupo particular, quienes en su estrecha relación con el poder estatal, cumplen con el papel de asimilar desde el punto de vista ideológico al resto de los intelectuales. A partir de estos planteamientos, en el caso venezolano pudieran señalarse dos cosas. En primer lugar, en la construcción de una historia sobre el pasado y presente de los pueblos indígenas venezolanos Vallenilla 
Lanz, Uslar Pietri y Guillermo Morón fungieron como intelectuales orgánicos, construyendo una mirada que puede resumirse en pocas frases: "Lo indígena es atrasado y debe desaparecer", "los indígenas no aportaron nada a la venezolanidad" y "los pocos grupos de indígenas que aún existen deben civilizarse". Estas afirmaciones fueron y siguen siendo repetidas hasta el cansancio por un sector importante de la intelectualidad venezolana. En segundo lugar, puede apreciarse que no existió un cambio en la mirada de los intelectuales que acompañaron a estos gobiernos "diferentes", justamente porque como señala Acosta (2012), los cambios fueron nominales y no en cuanto a los grupos sociales que detentaban el poder.

\title{
EL DISCURSO CINEMATOGRÁFICO SOBRE LOS PUEBLOS INDÍGENAS EN LA DÉCADA DE LOS AÑOS 80
}

\author{
La lucha por la hegemonía ideológico-politica es siempre una lucha \\ por la apropiación de aquellos conceptos que son vividos \\ espontáneamente como apoliticos \\ (Žižek, 2008, p. 15).
}

Como se ha planteado hasta ahora, la construcción ideológica del pasado y del presente con fines identitarios y políticos por parte de los sectores hegemónicos de la sociedad, se hace a través de los intelectuales orgánicos. Sin embargo, es importante mencionar que su difusión no se encuentra limitada a la producción de estos, ni a la que los intelectuales tradicionales siguiendo la línea de estos puedan hacer, la difusión de estas ideas a la sociedad se hace a través de lo que Althusser (1988) denominó Aparatos Ideológicos del Estado. Si bien plantea una lista de diversas instituciones que se presentan ante la sociedad como neutrales y que cumplirían la función de legitimar las posiciones del Estado difundiéndolas ante la sociedad, nos parece adecuado prevenir el error de clasificarlas por su naturaleza aparente, por el contrario todas sin excepción obedecen a la misma lógica y buscan de manera consciente o inconsciente transformar estos contenidos ideológicos en contenidos culturales, es decir en contenidos que la sociedad acepte por ciertos y que no tenga duda alguna de su "veracidad". Dentro de estos aparatos ideológicos los medios audiovisuales tienen cada vez más una mayor presencia e influencia en la sociedad. 
Las últimas décadas del siglo XX estuvieron caracterizadas por el emerger de los medios audiovisuales y su posicionamiento omnipresente en la sociedad. Estos medios han venido a tomar el papel que en el pasado tenían otras instituciones (como la Iglesia y la escuela) en la formación de las personas, su papel es tal en la sociedad contemporánea que algunos autores afirman que "son los ladrillos que construyen la cultura” (Buck-Morss, 2009, p. 38). Esta afirmación ratifica la importancia de estudiar las representaciones que se hacen del otro a través de las imágenes, debido a que muy probablemente estas representaciones pasen a formar parte del horizonte cultural de las personas a quienes van dirigidas.

A partir del análisis crítico del discurso que sobre los pueblos indígenas venezolanos construyen las producciones cinematográficas de ficción de la década de los años 80 , se pueden identificar algunos elementos divergentes y otros convergentes. En los divergentes se ubica la estética de la producción audiovisual, en la cual no nos detendremos mucho para dar paso al análisis crítico del discurso. En este aspecto se pueden identificar tres tendencias, la primera podría catalogarse de naturalista, en ella el indígena es ubicado como parte del escenario natural donde se desarrolla la película, es decir, el indígena es naturalizado en el paisaje, es cosificado como un objeto que forma parte de escenario donde se desarrolla película, para el director el escenario está constituido por la selva, los campesinos, los animales salvajes y los indígenas, en esta categoría se ubica a la película Caballo salvage (1981) de Joaquín Cortés, la cual relata la vida de los llaneros venezolanos. La segunda categoría la denominamos cine conquista militar, en ella se ubican las películas del director Diego Rísquez, Orinoko, nuevo mundo (1984) y América, terra incógnita (1988) y del director Michel New, Cubagua (1987). En la primera, el cineasta muestra una mirada a los procesos de colonización y conquista de los territorios americanos, donde se muestra en escenarios naturales la conquista militar y religiosa sobre los pueblos indígenas venezolanos, en la segunda, se muestra una mirada sobre los procesos de mestizaje en el territorio americano, ambas destacan por su enfoque artístico, pero nada distan de las versiones oficiales de la historia que cuentan los intelectuales orgánicos que se analizaron en los capítulos anteriores. El indígena construido por Rísquez se inscribe en la noción de buen salvaje rousseauniana, donde los nativos vivían en un paraíso terrenal del cual son expulsados por la codicia y crueldad de los españoles. Cubagua sigue esta misma línea trazada por Rísquez, aunque inspirada en la novela 
de Enrique Bernardo Núnez del mismo nombre, esta película cuenta la historia de cómo los procesos de despojo y apropiación de la tierra por parte de los europeos, afectaron a las comunidades indígenas. La tercera categoría es la de cine conquista religiosa, donde se muestra en apariencia una crítica a los procesos de colonización y conquista liderados por la Iglesia católica, en esta categoría se ubica la película $\mathrm{Ya}$-koo (1985) de Franco Rubertelli, que muestra la historia de la conquista religiosa de las comunidades indígenas venezolanas.

Sin embargo, a lo largo de este artículo se ha enfatizado en la necesidad de estudiar al cine como un producto cultural que da cuenta de ideas que se producen en el seno de una formación económico-social particular, y que tienen como finalidad última la de servir a las construcciones identitarias que el poder estatal promueve. Desde esta mirada, y siguiendo los principios metodológicos del paradigma indiciario de Ginzburg, es posible apreciar elementos comunes a todas las producciones cinematográficas de la década de los años 80 y resumirlos en tres características principales. La primera de ellas es la exoticidad, es decir, lo indígena es representando siempre como algo exótico y totalmente ajeno a la venezolanidad, para apoyar este discurso los realizadores llevan adelante sus producciones en lugares remotos, donde predomina una geografía de selvas, ríos, montañas y animales con los que la mayoría de la población nacional no tiene ningún tipo de contacto habitual, es decir, ese otro que representa el indígena a su vez es representado en un espacio geográfico que también representan una otredad; como lo señala Amodio (1993):

\footnotetext{
"Dos posiciones semánticas intervienen fuertemente para definir la identidad específica de cada cultura: adentro/afuera, por lo que se refiere a las categorías espaciales y la definición del territorio; nosotros/ellos por lo que se refiere a las categorías de identidad cultural" (p. 17).
}

El discurso fílmico de la representación del indígena va acompañado de la representación del lugar en el que dicho discurso ubica a ese otro, ratificando de esta forma las posiciones semánticas sobre lo que es ser indígena y dónde se ubica; y de lo que es ser "civilizado" y dónde se ubica. Así mismo, se refuerza constantemente la idea de la división de lo "natural" y lo "social", colocando siempre a los indígenas como parte del paisaje natural. Solo empiezan a formar parte de la "sociedad" en 
el momento en que abandonan sus formas de entender el mundo y abrazan las formas occidentales. Es importante destacar que estas divisiones de nosotros/ellos, adentro/afuera y social/natural, no son nuevas y por el contrario son comunes en la representación del indígena que hacen los intelectuales orgánicos en su construcción del pasado y presente de los pueblos indígenas venezolanos, lo nuevo en este caso corresponde a que este discurso de la historia oficial tome forma de película y se construya a través de las imágenes.

Otro elemento común de este discurso cinematográfico tiene que ver con el lenguaje, característica que, como señalan diversos autores, es central para diferenciar lo humano de lo no humano. Por ello, llama poderosamente la atención que en ninguna de las películas estudiadas las lenguas indígenas fueron traducidas bajo ninguno de los recursos clásicos del cine (subtítulos o traducción de los propios personajes), es decir, todos los directores optaron por silenciar las lenguas indígenas omitiendo su traducción para de esta forma negar la posibilidad de inteligibilidad de las mismas, siempre que pusieron en diálogo a los pueblos indígenas con la sociedad hegemónica occidental usaron el lenguaje de los dominantes, y cuando el diálogo se dio entre miembros de los pueblos indígenas optaron por no transmitir al público los significados de estos, lo que muestra claramente el espectro semántico en el que se ubican los productores de estas películas, es decir, deja claramente especificado cuál es el adentro y cuál es el afuera y quiénes son el nosotros y quiénes el ellos. Legitimando así las posturas ideológicas, pretendidas científicas, que desde los primeros momentos de la conquista de los territorios americanos se han divulgado con respecto a las lenguas indígenas, las cuales para algunos de nuestros "científicos" e "intelectuales" no tienen el carácter de lengua y se les define a lo sumo como dialectos.

Por último, pero no menos importante, el tercer elemento común del discurso cinematográfico sobre los pueblos indígenas durante la década de los años 80 es la noción de civilización, los directores constantemente marcan una línea divisoria entre lo que ellos consideran civilizado y lo que consideran salvaje, y en esta línea divisoria siempre ubican a los pueblos indígenas del lado de lo salvaje, condición que en el discurso cinematográfico deben "superar". Estos elementos hablan por sí solos de la posición de alteridad que ocupan los pueblos indígenas para los productores cinematográficos de la época, puesto que reafirman lo planteado por Bitterli cuando 
indica que "bárbaro, salvaje y pagano, son antónimos de aquello por lo que uno se toma a sí mismo" (1982, p. 445, citado en Amodio, 1993, p. 23). Al respecto DunoGottberg (2008) también plantea la necesidad de exotización del indígena como una forma de advenimiento de una sociedad moderna, donde la estética indígena debía adecuarse a las nuevas realizadas de esa Venezuela moderna que el petróleo de la época pretendía comprar.

Desde la década de los años 70, esta construcción sobre los pueblos indígenas en los medios de comunicación venía siendo fuertemente criticada por las organizaciones políticas indígenas como CONIVE, quienes denunciaron en su momento que la televisión y el cine promovían una visión sobre el pasado y presente de los pueblos indígenas caracterizada por:

1. Indígenas en un estado total de salvajismo, o en vías de desaparición, a quienes solo les queda plegarse a la cultura que nos quieren imponer o resignarnos a la progresiva desaparición física y cultural.

2. Se hace una justificación y casi exaltación del proceso de conquista española y de sus consecuencias, y un corte ideológico entre el pasado precolombino y la sociedad venezolana actual.

3. A la resistencia indígena se le da un valor exclusivamente simbólico y al mismo tiempo inoperante y antihistórico (CONIVE, 1973, citado en Arreaza, 2010, p. 135).

Estos tres elementos también pueden encontrarse en la construcción del otro escrita en los diarios de los cronistas de los primeros momentos de la Conquista de América, en los posteriores viajeros que visitaron las regiones americanas y en la construcción de la historia oficial que hemos mencionado anteriormente encarnada en los tres intelectuales orgánicos estudiados, es decir, como se indicó, la construcción ideológica del indígena en el cine ficción venezolano en la década estudiada no es nueva, lo nuevo es el medio por el que se hace, es decir, asistimos a una década en el que la historia enseñada toma los espacios cinematográficos y de esta forma, legitimados por la supuesta neutralidad política del cine, consolidan la visión que de la sociedad 
venezolana tienen las elites. El enfrentamiento político, entendida en la dimensión cultural y simbólica de la política señalada por Gramsci (1932), que por muchos años se dio en distintos escenarios académicos e intelectuales sobre las visiones del pasado y particularmente sobre el pasado de los pueblos indígenas, se traslada al cine, con la particularidad y la ventaja para los grupos hegemónicos de que son estos los únicos que para esta década se encuentran en la capacidad tecnológica de producir versiones audiovisuales del pasado y transmitir a la sociedad sus representaciones del otro.

\section{CONSIDERACIONES FINALES}

Los procesos de construcción y reconstrucción del pasado tendrán siempre como una de sus características la influencia que recibirán desde el presente, es decir, de una u otra manera los relatos históricos tributarán en menor o mayor medida al presente donde son generados y al grupo social que lo construye. Esta situación obliga a revisar constantemente no solo los documentos históricos (que como hemos visto pueden ser de diversa índole, no solo textos escritos), sino también sus contextos de producción, así como los sectores sociales a los que pertenecían quienes produjeron y los intereses de estos sectores sociales, puesto que muy frecuentemente las construcciones históricas terminan por ofrecer más información del grupo social que las produce que de los grupos sociales que estos pretenden historiar. Al analizar al cine como un productor histórico y cultural de su tiempo debemos tener presente estas mismas consideraciones, sobre todo cuando este cine pretende representar a grupo sociales que históricamente han sido invisibilizados.

Este recorrido por el cine ficción venezolano ha permitido realizar un análisis acerca del discurso que sobre los pueblos indígenas está contenido en sus producciones, del cual se pueden concluir tres elementos de suma importancia. El primero de ellos tiene que ver con el papel de los intelectuales orgánicos en la sociedad, a los que muchas veces se les atribuye un papel distante de las grandes masas, y que por el contrario vemos cómo sus ideas se transmiten de forma masiva y cómo sus contenidos ideológicos se transforman en contenidos culturales para la sociedad, al punto que muy probablemente amplios sectores de la sociedad nunca habrán leído un libro de 
estas características, pero la versión de la historia que manejan y asumen como cierta será la producida por ellos.

El segundo elemento tiene que ver con el cine como una herramienta para la difusión de contenidos ideológicos en la sociedad, puesto que el mismo funge como herramienta que construye y consolida como imaginarios de la sociedad todas las ideas e imaginarios de aquellos sectores sociales que se encuentran en la capacidad tecnológica de producir discursos cinematográficos, es decir, transforma en "realidad" las ideas, miedos y sentimientos que las clases dominantes tienen para con el resto de la sociedad. En el caso específico de los pueblos indígenas el cine viene a consolidar ese imaginario sobre los pueblos indígenas que viene desde tiempos coloniales y que se difundió a toda la sociedad a través de los diferentes medios como la radio, televisión y programas educativos. Imaginario que puede resumirse en pocas frases "los indígenas son salvajes y atrasados" "los indígenas deben civilizarse" y por último, pero no menos importante: "los indígenas no aportaron nada a la sociedad venezolana".

El tercero de los elementos tiene que ver con la posibilidad cierta de que el futuro permita una producción cinematográfica no solo hegemónica, sino también contrahegemónica y la apropiación tecnológica le brinde la oportunidad a los sectores de la sociedad que fungen como representados en este cine, de construir visiones alternativas de presente y pasado, pero sobre todo que tengan la posibilidad cierta de representarse a sí mismos y representar socialmente a esos otros que hoy los representan. 


\section{ReFERENCIAS}

Acosta, M. (1948). Un mito racista: el indio, el blanco, el negro. Revista Nacional de Cultura, 97-98.

Acosta, M. (1961). Estudios de etnología antigua de Venezuela, (volumen 2). Caracas: Universidad Central de Venezuela.

Acosta, M. (2012). Habla Miguel Acosta Saignes, entrevista realizada por Agustín Blanco Muñoz. Caracas: Universidad Central de Venezuela.

Acosta, J. M. (2003). Entorno teórico-metodológico para historiar el cine venezolano. Akademos, 5(1), pp. 35-56.

Althusser, L. (1988). Ideología y aparatos ideológicos de Estado: Freud y Lacan. Buenos Aires: Nueva visión.

Amodio, E. (1993). Formas de la alteridad: construcción y difusión de la imagen del indio americano en Europa durante el primer siglo de la conquista de América. Quito: Ediciones Abya-Yala.

Amodio, E. (1999). El mito del crisol: razas, etnia e historia. En Lino M., Jacqueline C., y Gladys G. (Eds.). Hacia una antropología del Siglo XXI. Mérida: Universidad de los Andes.

Arráiz, R. (2010). Arturo Uslar Pietri: ajuste de cuentas. Prodavinci. Recuperado de http:// prodavinci.com/2010/02/26/artes/arturo-uslar-pietri-ajuste-de-cuentas/

Arreaza, E. (2010). Representación del indígena en el cine venezolano de ficción. Fermentum, revista venezolana de Sociología y Antropología, 20(57), pp. 130-150.

Barreto, D. (1995). Identidad, etnicidad, antropología. Boletín americanista, (45), pp. 7-21. 
Buck-Morss, S. (2009). Estudios visuales e imaginación global. Revista de Antropología y Arqueología Antipoda, (9), pp. 19-46.

Castillo, O. (2003). Los años del buldózer: ideología y politica, 1948-1958. Fondo Editorial Tropykos.

Crespo, A. (2009). El cine y la industria de Hollywood durante la Guerra Fría, 1946-1969. Tesis para optar al grado de licenciado en Letras. Universidad Autónoma de Madrid.

Duno-Gottberg, L. (Ed.). (2008). Miradas al margen: cine y subalternidad en América Latina y el Caribe. Fundación Cinemateca Nacional.

Fukuyama, F. (1992). El fin de la historia y el último hombre. Madrid: Editorial Planeta.

Gaskell, I. (1996). La historia de las imágenes. En Burke, P. (Ed.). Formas de hacer historia. Madrid: Alianza Universidad.

Ginzburg, C. (2004). Huellas. Raíces de un paradigma indiciario. Tentativas, Universidad Michoacana de San Nicolás de Hidalgo, México, pp. 93-155.

Gramsci, A. (1932). Cuadernos de la cárcel: cuaderno 12. Recuperado de http://www.gramsci. org.ar/TOMO2/1_formac_intelelectuales.htm

Guzmán, N. (2009). Ludovico y Marx. En Silva, L. (Ed.). Antimanual para uso de marxistas, marxólogos y marxianos. Caracas: Monte Ávila Editores Latinoamericana.

Harwich, N. (1983). Arma y coraza. Biografía intelectual de Laureano Vallenilla Lanz. Caracas: Universidad Santa María.

Horkheimer, M. y Adorno, T. (1988). La industria cultural. Iluminismo como mistificación de masas. Buenos Aires: Editorial Sudamericana.

Iglesias, P. (2013). Maquiavelo frente a la gran pantalla: cine y politica. Madrid: Ediciones Akal. 
Lévi-Strauss, C. (1995). Antropología estructural. Barcelona: Ediciones Paidós.

Marx, K., y Engels, F. (2013). La ideología alemana. Tomo I. Caracas: Editorial el Perro y la Rana.

Mauss, M. (1979). Sociología y Antropología. Madrid: Editorial Tecnos.

Mora-García, P. (2004, enero-diciembre). El currículum como historia. Revista de Teoría y Didáctica de las Ciencias Sociales, (9), pp. 49-74.

Mora, J. (2017). El cine documental 'radical' y la construcción de historias subalternas. Reflexiones en torno al film Sabino vive, las últimas fronteras (2014). Nóesis. Revista de Ciencias Sociales y Humanidades, 26(51), pp. 58-83. doi: http://dx.doi.org/10.20983/noesis.2017.1.4

Morón, G. (1971). Historia de Venezuela (tomo I). Caracas: Editorial Italgráfica.

Navarrete, R. (2006). Analogías poderosas: el uso de la analogía para el estudio arqueológico de la complejidad social prehispánica y colonial temprana en el oriente venezolano. Boletín Antropológico, 24(67), pp. 221-258.

Nietzsche, F. (2008). El origen de la tragedia. Buenos Aires: TerraMar Ediciones.

Pereira, G. (2010). Los seres invisibles. Caracas: Editorial el Perro y la Rana.

Salas, J. C. (1908). Tierra-firme (Venezuela y Colombia): Estudios sobre Etnología e Historia. Tipografia. de la Paz y Trabajo.

Salas, J. C. (1977). Civilización y barbarie, (1). Ediciones Centauro.

Silva, L. (2011). La plusvalía ideológica. Caracas: Fundarte.

Vargas, I. (2005). Visiones del pasado indígena y el proyecto de una Venezuela a futuro. Revista Venezolana de Economía y Ciencias Sociales, 11(2), pp. 187-210.

Žižek, S. (2008). En defensa de la intolerancia. Buenos Aires: Sequitur. 